\title{
Interactive comment on "Long-term Variations in Ozone Levels in the Troposphere and Lower Stratosphere over Beijing: Observations and Model Simulations" by Yuli Zhang et al.
}

Yuli Zhang et al.

liuyi@mail.iap.ac.cn

Received and published: 6 May 2020

Thanks for all the comments and suggestions. We have carefully revised the manuscript according to these suggestions. Our point-to-point responses are listed below:

Major comments: (1) A sudden drop in lower tropospheric ozone (<3 km) after 2011 is surprising. It is inconsistent with satellite NO2 data shown in Fig 5 (and NOx emission inventory) which indicate gradual decrease in NOx emission after 2011 . Recently reported surface measurements at two rural sites near Beijing (Shangdianzi and Gucheng) also did not observe sudden ozone drop around 2011/12 (Xu et al., 2020). I 
suggest comparing satellite observed tropospheric ozone to verify the sudden change observed in the present study. If no problem is found on data quality, the stepwise change is most likely due to change in large scale dynamics after 2011 . The stratospheric model used in this study shows little change in stratospheric contribution to lower tropospheric ozone, but it may be the case that transport within the troposphere played a role. I suggest author add more analysis in this direction. For example, back trajectories can be calculated to see if there was change in transport from other parts of troposphere after 2011. Reply: We compared ozonesonde to OMI observation (Fig. A) as suggested. The data quality of $\mathrm{OMI}$ in troposphere is not as good as in stratosphere, especially in lower troposphere where there are often missing values in dataset. Even so, the sudden drop in the period of 2011-2012 are still found in middle troposphere and especially in UTLS. So, we believe the data quality of ozonesonde and the sudden drop we found are reliable. The reason for this sudden drop may mainly due to the changes in UTLS rather than NOx emission. Because the sudden drop is also found in CLaMS simulation which has no tropospheric ozone chemistry.

(2) The trend analysis can be improved; it is not clear why the trend calculation in the main text is different from the linear regression shown in the figures. In addition, the level of statistical significance in trend analysis should be provided. Reply: We checked every value of trend in the main text, and they are the same as the linear regression in the figures. We add statistical significance testing in the $\mathrm{O} 3$ and $\mathrm{NO} 2$ trends, most of them passed the 95\% significance criterion. For the seasonal $\mathrm{O} 3$ trends, most ozonesonde trends in lower troposphere and mid-troposphere before 2012 passed the $95 \%$ significance criterion. Since there are fewer samples after 2012, some trends only passed the $90 \%$ significance criterion.

(3) The lower tropospheric ozone in the present study appeared to have a small positive trend after the 2011 drop (Fig 3). This trend is not supported by author's contention that NOx reduction has decreased ozone. It is instead similar to surface ozone increase observed in many urban areas from the Ministry of Ecology and Environment network

Printer-friendly version

Discussion paper
Interactive

comment 
since 2013, which has been attributed to the nonlinear chemistry of ozone precursors (NOx emission decrease and VOC emission increase) and aerosol decrease, as well as being affected by meteorological variation (see for example, Li et al., 2019; Liu and Wang, 2020). Reply: We noticed that O3 trend is still positive after the 2011 drop, but it is much slower than before due to the reduction of NOx. However, there are other precursors which might be responsible for the small positive trend after the 2011 drop. Thanks for showing us the two papers (Li et al., 2019; Liu and Wang, 2020). We added them when we mentioned the possible reasons of meteorological variation in the discussion and conclusions.

Minor comments: Page 2, line 40-42, "Increasing surface ozone . .." . Please note that recent studies have shown levelling off/decrease in surface ozone levels in rural areas of eastern China and in outflow of eastern China air masses (Xu et al., 2020; Wang et al., 2019). Reply: We added the recent studies which show the decrease in surface ozone levels in next paragraph.

Page 2, line 56, Consider modifying the statement "it is not known. . ." as it contradicts the author's earlier review of Dufour (2018) on the lower tropospheric ozone trend in NCP (which includes Beijing). Reply: We modified this sentence.

Page 2, line 100, Define "average percentage method", and clarify why a different (linear regression method) is used in the figures. Reply: we explained the method. The method is used to remove the seasonality in the time series. As a result, we got deseasonalized $\mathrm{O} 3$ (black dots in figures). Linear regression method is applied on the deseasonalized $\mathrm{O} 3$ to get the trend of $\mathrm{O} 3$. These methods are used on different steps for different purpose.

Interactive comment on Atmos. Chem. Phys. Discuss., https://doi.org/10.5194/acp-2019-1145, 2020. 
(a) Deseasonalized 9 - $15 \mathrm{~km}$ O3 column by OMI

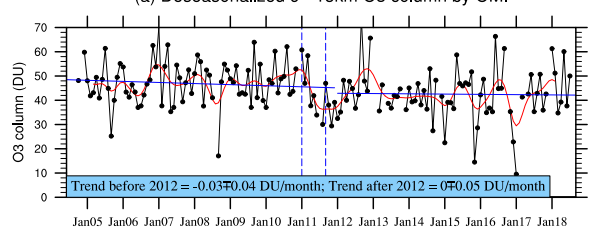

Interactive

comment

(b) Deseasonalized 3 - 9km O3 column by OMI

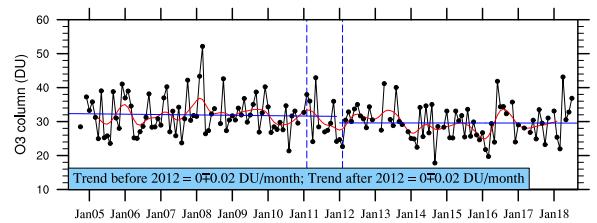

(c) Deseasonalized 0 - 3km O3 column by OMI

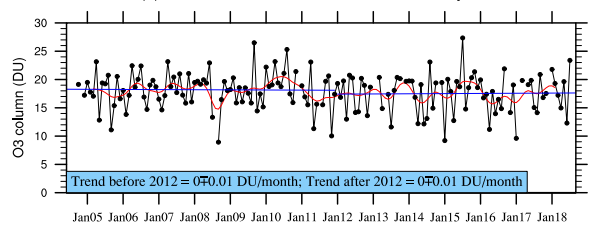

Printer-friendly version

Fig. 1. Figure A. Deseasonalized monthly mean partial columns of ozone over Beijing (black solid lines and dots) measured by OMI and the corresponding Gaussian-weighted means using a half-width of 12 months 